\title{
STUDY OF TUMOR MICROENVIRONMENT AND HOST RESPONSE IN COLORECTAL CANCER: IMMUNOHISTOCHEMICAL AND CLINICOPATHOLOGICAL APPROACH
}

\section{NORIA OTHMAN RAFFALLA ${ }^{1 *}$, SUZAN MOHAMED FAROUK HELAL ${ }^{2}$, AMANY ABD EL-BARY ABD EL-LATIF $^{2}$, RASHA OMAR ELSAKA ${ }^{3}$}

${ }^{1}$ Department of Pathology, Faculty of Medicine, University of Omar Al-Mukhtar, Al Bayda, Libya. ${ }^{2}$ Department of Pathology, Faculty of Medicine, University of Alexandria, Alexandria Governorate, Egypt. ${ }^{3}$ Department of Clinical Oncology and Nuclear Medicine, Faculty of Medicine, University of Alexandria, Alexandria Governorate, Egypt. Email: noriaothman@yahoo.com

Received: 01 October 2019, Revised and Accepted: 31 October 2019

ABSTRACT

Objective: This study aimed to evaluate the immunohistochemical expression of forkhead boxP3 (Foxp3), CD8, CD68, and CD21 in stroma between tumor cells of colorectal cancer (CRC) patients and examines the relationship between these variables and clinicopathological parameter and patients' prognosis.

Methods: In this work, 50 cases of colorectal carcinomas were included and immunohistochemical evaluation of Foxp3, CD8, CD68, and CD21 in tumor tissue samples.

Results: Tumor-infiltrating lymphocytes (TILs) including cytotoxic T cells and regulatory T cells as well as tumor-associated macrophages and follicular dendritic cells (FDCs) were studied in the stroma of the tumor using immunostaining technique for CD8, Foxp3, CD68, and CD21, respectively. Cases were followed up. CD8-positive cytotoxic T cells, Foxp3-positive regulatory T cells, and CD21 positive-FDCs were significantly more pronounced in early tumors and those with longer overall survival. On the other hand, CD68 positive macrophages were more encountered in late stage and metastatic tumors as well as tumors with shorter overall survival, but these results not reached the level of significance.

Conclusion: We concluded that (TILs) and FDCs are conferring better prognosis in CRCs, they may act synergistically in stimulating a protective immune response in the tumor microenvironment that hinders tumor progression, while the role of tumor-associated macrophages in CRCs is still controversial and needs further studies.

Keywords: Colorectal cancer, Lymphocyte subsets, Tumor-associated macrophage, Tertiary lymphoid structure, Survival.

(c) 2020 The Authors. Published by Innovare Academic Sciences Pvt Ltd. This is an open access article under the CC BY license (http://creativecommons. org/licenses/by/4. 0/) DOI: http://dx.doi.org/10.22159/ajpcr.2020.v13i1.35940

\section{INTRODUCTION}

Colorectal cancer (CRC) is one of the most common solid cancer affecting both sexes nearly $10 \%$ of total cancer cases [1,2]. In Egypt, CRC occupies first rank among digestive system malignancies and fifth rank among total cancers [3]. Mortality related to CRC has descended gradually in many Western countries, which can be imputed to cancer screening programs and early detection. However, rates have continued to increase in our developing countries with poor health-care resources $[4,5]$.

Despite the great amelioration in early diagnosis, the prognosis of CRC patients remains far from satisfaction; this enhances efforts for improvement of new prognostic markers for risk stratification in CRC. The era of tumor microenvironment (TME) is now widely studied for this purpose [6]. Stromal cells can both promote and inhibit tumor cell growth. Now cancer research has recently shifted from studying tumor cells itself to evaluation of cells and mediators encountered in TME [7]. From the wide variety of cells and factors constituting TME, collectively lymphoid neogenesis in the form of lymph node-like structures [8-10] or individually infiltrating immune cells are attracting great attention. These cells are playing a fateful role in tumor progression through a complex interaction with all other components of TME. However, those interactions are still convoluted and argumentative issues were reported on it $[11,12]$. The association of immune system activity and prognosis in CRC was described for a long time [13]. In this work, we study the tumor-infiltrating lymphocytes (TILs) and its correlation with other clinicopathological parameters in CRC.

\section{METHODS}

The present retrospective study included 50 cases of CRC submitted to pathology then to the Clinical Oncology Department, Faculty of Medicine, University of Alexandria, during the period between January 2013 and December 2016. Follow-up data were obtained by reviewing charts and tumor registry records. Cases with insufficient tumor sample, unavailable clinical information, and pretreated colorectal carcinomas were excluded from the study.

The study was approved from the Ethics Committee before work conduction.

\section{Histopathology}

Formalin-fixed paraffin-embedded blocks of the included 50 cases of colorectal carcinomas were cut into $5 \mu \mathrm{m}$ - thick section and stained by $\mathrm{H}$ and $\mathrm{E}$ for confirmation of the histologic diagnosis, subtyping, grading, and assessment of other histologic features.

\section{Immunohistochemistry}

Staining was performed using streptavidin - biotin-peroxidase complex technique using the following antibodies, forkhead boxP3 (Foxp3) (clone 236A/E7), CD68 (clone KP1), CD8 (C8/144B), and $\mathrm{CD} 21)$ clone $\mathrm{FBCI}$ ). Sections of the tonsil were included as positive control for the four antibodies used (as recommended by the manufacture's protocols) [14]. Sections without primary antibodies served as negative control. 
Scoring of immunohistochemical staining

Slides for each antibody were separately examined under low and high power light microscopic examination for semiquantitative assessment of antibody - staining

Positive CD68 was defined as cytoplasmic staining of the macrophage (Fig. 1e and f); percentage was evaluated using semiquantitative method described by Jakovic et al. ten randomly selected high power fields $(\times 400)$ were selected in the stroma infiltrated by inflammatory cells [15].
TIL including Treg and cytotoxic T lymphocytes subsets in CRC was determined immunohistochemical evaluations of Foxp3 and CD8, respectively, expression. Foxp $3^{+}$TIL was counted in five randomly selected high power fields at $(\times 400)$ magnification in the stroma of cases according to method described by Takenaka et al. Positive Foxp3 was defined as nuclear or cytoplasmic staining (Fig. 1a and b), the percentage of (Foxp3) stained cells was scored according to four grades scoring systems. (0): Negative, (1+): 1-25\%, (2): 26-50\%, and (3): $51-100 \%[16]$.
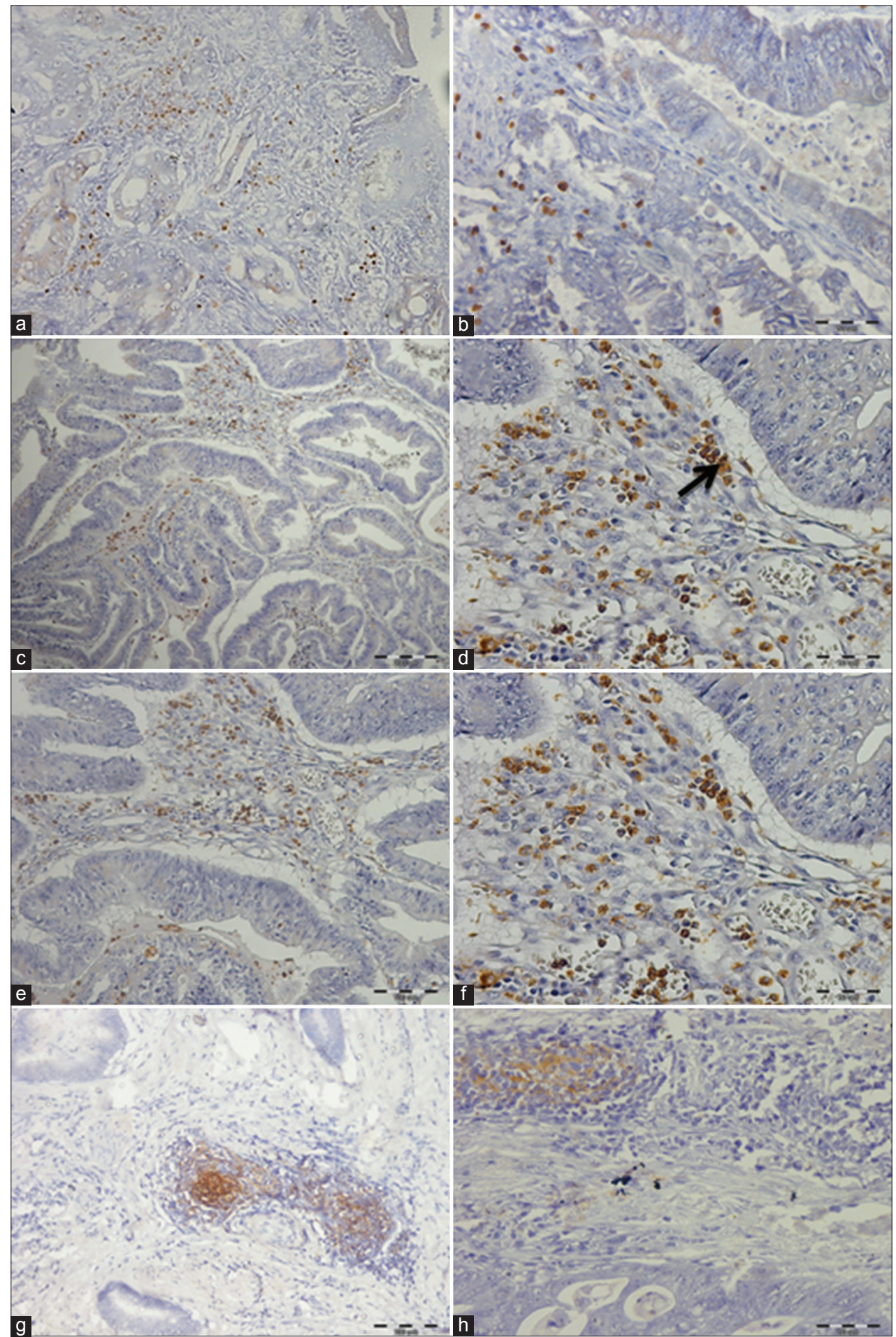

Fig. 1: Expression of immune markers in CRC cases. - Ax100, Bx400 Foxp3 (brown nuclear) in the stroma. C x200, Dx400: CD8 (positive T cells) the arrow indicate positive cells. Ex100, Fx400: CD68 (positive tumor associated macrophage in the stroma of CRC biopsy). G x100, Hx200: TLS immunostained with an antibody against CD 21 
Positive (CD8) was defined as membranous \pm cytoplasmic staining (Fig. 1c and d). The percentage of CD8 stained cells was assessed according to scoring systems described by Chen et al. [17].

CD21 ${ }^{+}$follicular dendritic cell (FDC) was defined as formed a tight network within thefollicle as shown in Fig. $1 \mathrm{~g}$ and $\mathrm{h}$ and was evaluated as either positive or negative staining according to the method described by Trajkovski et al. [10].

\section{Follow-up}

Cases were followed up for a period of 4 years. New events including tumor recurrence or metastasis were documented.

\section{Statistical analysis}

Data were fed to the computer and analyzed using IBM SPSS software package version 20 and Microsoft Office Excel 2010. Chi-square test was used to compare different groups. The significance of the obtained results was set at $\mathrm{p}<0.05$.

\section{RESULTS}

In the studied 50 cases of CRC, the age of the patient ranged from 22 to 80 years with a mean of $48.28 \pm 12.23$ years. Clinical and histologic data of the studied cases were summarized in Table 1.

\section{Results of immunostaining}

The mean for Foxp3, CD68, and CD8 was 58.0 $25.99,68.30 \pm 13.61$, and $46.50 \pm 29.90$, respectively, while positive CD21 was detected in $29 / 50$ cases $(58 \%)$.

Results of immunostaining and its correlation with other clinicopathological parameters were summarized in Table 2 .

Foxp3 staining density was significantly higher in low grade $(\mathrm{p}=0.005)$ and low stage tumors $(\mathrm{p}=0.021)$.

The mean of $\mathrm{CD}^{+}$ve CTC was significantly higher in males (mean $60.0 \pm 29.83, \mathrm{p}=0.042$ ), in the right-sided colon than other sites (mean $54.38 \pm 32.60, \mathrm{p}=0.042)$, non-mucinous histological type $(\mathrm{p}=0.036)$, and low grade $(\mathrm{p}=0.018)$ tumors. The mean CD8 staining was higher in Stage I, II than Stage III but the result was statistically insignificant $(\mathrm{p}=0.0 .616)$.

$\mathrm{CD}^{+}{ }^{+} \mathrm{ve}$ macrophage percentage was significantly higher in the rightsided colon than other sites $(\mathrm{p}=0.043)$

CD21 was significantly correlated with non-mucinous histological type $(\mathrm{p}=0.021)$ and low stage tumors $(\mathrm{p}=0.004)$.

\section{Results of follow-up}

During the period of follow-up, five cases developed metastasis. As regards the correlation with immunostaining, the overall survival was significantly higher in cases expressing high Foxp3 $($ mean $=55.80$ ) in comparison to those with lower Foxp3 expression (mean $=34.10$ ) ( $\mathrm{p} \leq 0.001)$ (Fig. 2a)

The overall survival also was higher in cases expressing high CD8 staining $($ mean $=53.89)$ than those with lower CD8 expression $($ mean $=35.0)(p=0.014)$ (Fig. 2b).

Overall survival was higher in cases with low expression of CD68 (mean $=34.0$ ) than those with reveals high expression (32.70), but this result was statistically insignificant ( $\mathrm{p}=0.665$ ) (Fig. 2c)

Overall survival was higher (mean $=55.0$ ) in cases shows CD21 positively stained FDC cells than cases did not show positive staining $($ mean $=41.29)(p=0.043)($ Fig. $2 d)$.

\section{DISCUSSION}

TME has a key role in the breakdown of prison on tumor cells to interact with surrounding environment. CRC, identical to most other solid
Table 1: Summary of clinical and histologic data of the studied cases

\begin{tabular}{|c|c|c|}
\hline Characteristic & $\mathbf{n}$ & $\%$ \\
\hline \multicolumn{3}{|l|}{ Age } \\
\hline$\leq 50$ & 29 & 58.0 \\
\hline$>50$ & 21 & 42.0 \\
\hline \multicolumn{3}{|l|}{ Sex } \\
\hline Male & 11 & 22.0 \\
\hline Female & 39 & 78.0 \\
\hline \multicolumn{3}{|l|}{ Size } \\
\hline$\leq 5 \mathrm{~cm}$ & 31 & 62.0 \\
\hline$>5 \mathrm{~cm}$ & 19 & 38.0 \\
\hline \multicolumn{3}{|l|}{ Tumor location } \\
\hline Right colon & 16 & 32.0 \\
\hline Left colon & 17 & 34.0 \\
\hline Rectosigmoid & 11 & 22.0 \\
\hline Rectum & 6 & 12.0 \\
\hline \multicolumn{3}{|l|}{ Histologic type } \\
\hline Non-mucinous & 35 & 70.0 \\
\hline Mucinous & 15 & 30.0 \\
\hline \multicolumn{3}{|l|}{ Grade } \\
\hline Low grade & 41 & 82.0 \\
\hline High grade & 9 & 18.0 \\
\hline \multicolumn{3}{|l|}{ Stage } \\
\hline I & 9 & 18.0 \\
\hline II & 21 & 42.0 \\
\hline III & 20 & 40.0 \\
\hline \multicolumn{3}{|l|}{ Follow-up data } \\
\hline Free & 45 & 90.0 \\
\hline Relapse & 5 & 10.0 \\
\hline
\end{tabular}

Table 2: Results of immunostaining and its correlation with other clinicopathological parameters

\begin{tabular}{|c|c|c|c|}
\hline Parameter & $\begin{array}{l}\text { Forkhead } \\
\text { boxP3 density } \\
\text { Mean } \pm \text { SD }\end{array}$ & $\begin{array}{l}\text { CD8 } \\
\text { density } \\
\text { Mean } \pm \text { SD }\end{array}$ & $\begin{array}{l}\text { CD68 } \\
\text { density } \\
\text { Mean } \pm \text { SD }\end{array}$ \\
\hline \multicolumn{4}{|l|}{ Sex } \\
\hline Male & $60.0 \pm 28.37$ & $60.0 \pm 29.83$ & $95.91 \pm 17.15$ \\
\hline Female & $57.44 \pm 25.65$ & $42.69 \pm 29.17$ & $68.97 \pm 12.63$ \\
\hline Significance (p) & 0.602 & $0.042^{*}$ & 0.831 \\
\hline \multicolumn{4}{|l|}{ Size } \\
\hline$\leq 5$ & $60.16 \pm 24.24$ & $51.29 \pm 29.07$ & $65.97 \pm 14.52$ \\
\hline$>5$ & $54.47 \pm 28.96$ & $36.68 \pm 30.36$ & $72.11 \pm 11.34$ \\
\hline Significance (p) & 0.693 & 0.234 & 0.150 \\
\hline \multicolumn{4}{|l|}{ Site } \\
\hline Right colon & $65.31 \pm 24.46$ & $54.38 \pm 32.60$ & $72.50 \pm 14.26$ \\
\hline Left colon & $64.12 \pm 20.78$ & $52.35 \pm 29.85$ & $70.88 \pm 12.40$ \\
\hline Rectosigmoid & $44.55 \pm 30.12$ & $24.09 \pm 21.89$ & $65.0 \pm 12.45$ \\
\hline Rectum & $45.83 \pm 27.46$ & $50.0 \pm 18.17$ & $55.83 \pm 10.68$ \\
\hline Significance (p) & 0.064 & $0.042^{*}$ & $0.043^{*}$ \\
\hline \multicolumn{4}{|l|}{ Type } \\
\hline Non-mucinous & $61.0 \pm 23.85$ & $50.29 \pm 28.26$ & $69.29 \pm 13.29$ \\
\hline Mucinous & $51.0 \pm 30.13$ & $37.67 \pm 32.73$ & $66.0 \pm 14.54$ \\
\hline Significance (p) & 0.374 & $0.036^{*}$ & 0.465 \\
\hline \multicolumn{4}{|l|}{ Grade } \\
\hline Low & $63.41 \pm 23.44$ & $51.59 \pm 29.74$ & $68.54 \pm 13.98$ \\
\hline High & $33.33 \pm 23.58$ & $23.33 \pm 17.85$ & $67.22 \pm 12.53$ \\
\hline Significance (p) & $0.005^{*}$ & $0.018^{*}$ & 0.691 \\
\hline \multicolumn{4}{|l|}{ Stage } \\
\hline I & $64.44 \pm 27.55$ & $49.05 \pm 28.36$ & $66.67 \pm 12.25$ \\
\hline II & $65.24 \pm 19.20$ & $48.75 \pm 28.19$ & $68.10 \pm 15.20$ \\
\hline III & $47.50 \pm 29.0$ & $35.56 \pm 37.62$ & $69.25 \pm 13.01$ \\
\hline Significance (p) & $0.021^{*}$ & 0.616 & 0.862 \\
\hline
\end{tabular}

Significant level* if $\mathrm{p} \leq 0.05$

tumors has microenvironment rich in inflammatory cells including TIL and macrophage $[6,10]$.

Transcription factor Foxp3 immunostaining was used to highlight T-regulatory cells. In our study, Foxp3 expression was significantly 

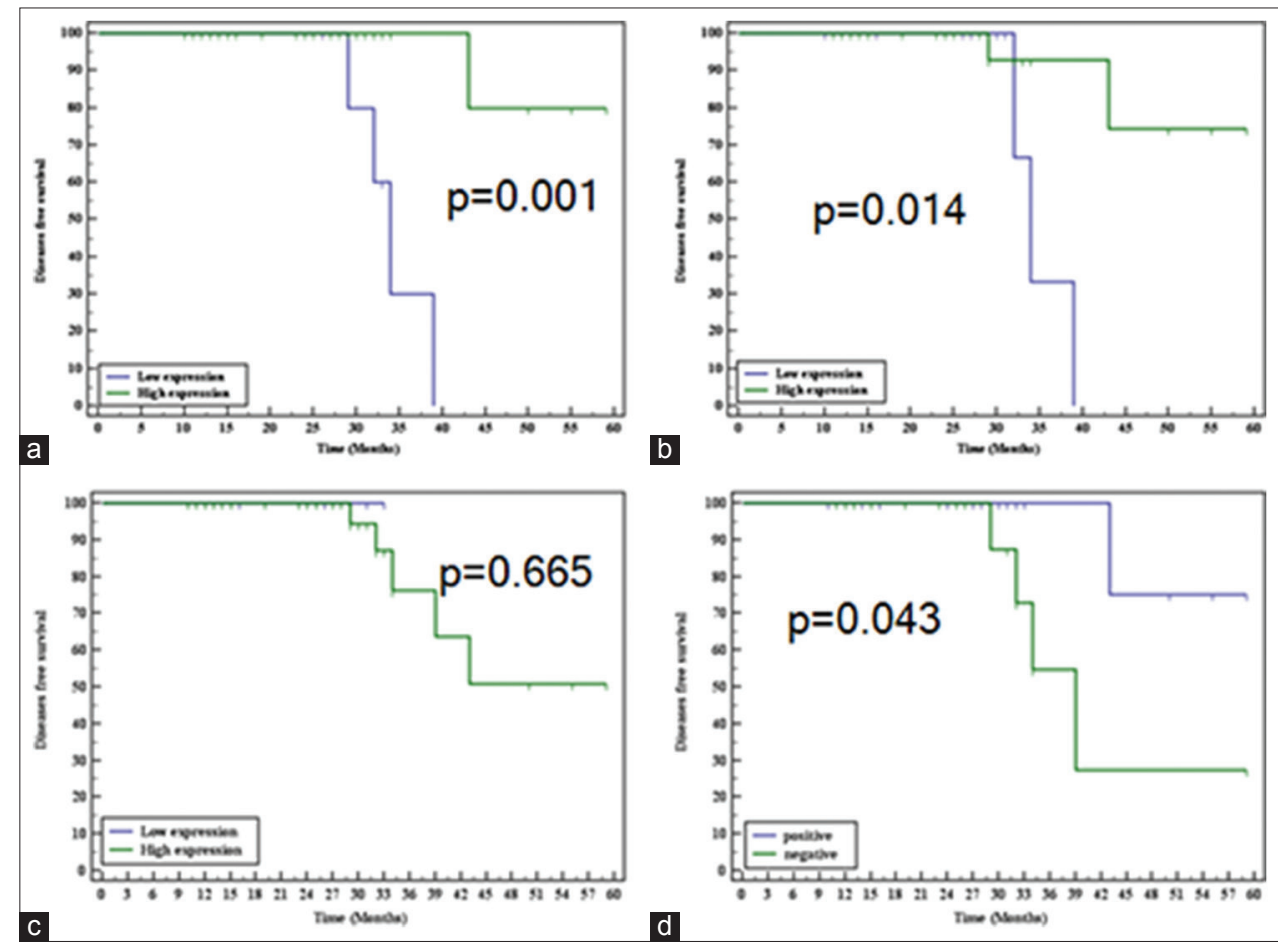

Fig. 2: Kaplan-Meier survival curves for disease-free survival and its correlation with immunomarkers (a) Forkhead boxP3, (b) CD8, (c) CD68, and (d) CD21

higher in early localized CRC (with low grade and low stage) with higher overall survival and disease-free survival. Controversial data were reported about Foxp3 in the literature, Sun et al. [18], Ling et al. [19], and Ladoire et al. [20] reported significance correlation between Foxp3 and early tumor grade and stage as well as longer survival which confirms that high-density Treg cells is related to a good prognosis, while Grimmig et al. [21] and Michel et al. [22] reported higher Foxp3 expression in aggressive tumors. Kim et al. [23] reported no significant difference in overall survival and tumor-infiltrating Treg cells.

The discrepancy among these results might be attributed to sample size and experimental methods where we concentrated on the TIL in tumor center and excluded the lymphocytes infiltrating peritumoral area. In addition some authors reported immune suppressive effect for Treg cells by secreting immune suppressive cytokines such as interleukin 10 and transforming growth factor-B into microenvironment of tumor tissue, which leads to immunological destruction and tumor promotion. These cytokines were considered in tumors such as breast, hepatocellular carcinoma, and ovary as unfavorable prognostic markers. While in other tumors as in CRC, head and neck cancer associated with good prognosis and improvement survival by its ability to reduce proliferative cytokine in milieu.

Moreover, Kim et al. [23] reported that cancer cells generated Foxp3 are associated with bad prognosis while its production by infiltrating Treg cells is associated with favorable prognosis in CRC, this may explain the discrepancy between our results and other results where we studied the total density of Foxp $3^{+}$ve Treg cells regardless of its origin.

Our study also included the assessment of macrophage density, at least two populations of macrophages with opposite immunological roles have been identified; as double edge swords, the M1 (classically activated) type with a proinflammatory antitumoral function and the M2 (alternatively activated) type with an immunosuppressive protumoral function $[24,25]$. It has been postulated that most of the tumor-associated macrophages belong to the M2 subtype [26]. For this reason, many studies attempted to trace tumor-associated macrophages using CD163 - a marker of M2 macrophages - with/without CD68.
However, a new hypothesis assumes that macrophages in vivo do not strictly follow the M1/M2 model, but rather tend to switch from one type to the other depending on the microenvironment activating signal they receive [26]. This being said, it is considered inappropriate to classify tumor-associated macrophages into either M1 or M2 type, but rather to consider them as a heterogeneous population playing different roles at different stages of tumor development [27-30]. Again, this may explain the discrepancy in the results of macrophages of different studies focusing on the prognostic role of macrophage in CRC including ours.

In the present work, immune histochemical identification was done using the most common and most commercially available routinely used pan-macrophage marker CD68 to include all macrophage populations in CRC, CD68 percentage was only significantly associated with site of tumor, with highest mean in right side of colon, although mean of CD68 was higher in Stage III, in metastatic, this difference was not statistically significant. Similar results were reported by Waniczek et al. [31] and Cui et al. [32] who concluded that increase intensity of macrophage is associated with unfavorable prognosis. Contradictory results were reported by Forssell et al. [33] and Li et al. [34] who found a significant positive correlation between intense infiltrations of CD68 and improved prognosis of CRC.

An additional explanation for this discrepancy may be also related to the heterogeneous distribution of macrophage in the different areas within same tumor, including tumor stroma, invasive borders, or peritumoral area as reported by Chaput et al. [35] who reported that of increase macrophage in tumor stroma of CRC is associated with poor prognosis and opposite finding with more macrophage at tumor in front which is associated with improve prognosis, in our study, we evaluated macrophage density in the stroma of CRC.

For CD8+CTC is reported that CTCs are having an antitumor effect through its capability to prohibit target cells on being exposed to tumor cell antigen/human leukocyte antigen 1 complex for which their $\mathrm{T}$ cell receptors are specific, leading to the destruction of tumor cells by apoptosis and this improving prognosis. Our results were concordant 
with results reported by Deschoolmeester et al. [36], Ling et al. [19], Sideras et al. [37], and Shibutani et al. [38], regarding the antitumoral effect of CTC as it was significantly higher in early non-metastatic tumors.

The developments of tertiary lymphoid structure (TLS) in tumors have been depicted in several other neoplastic such as lung and breast malignant melanoma.

Lymphoid neogenesis that develops within the tumor resembles the aggregation in secondary lymphoid. Many studies describe the relationship between TLSandclinical outcome intumors. TLS was detected microscopically by $\mathrm{H}$ and $\mathrm{E}$ staining and by immunohistochemistry in invasive CRC using CD21. TLS was found in (58\%) of cases. There was a statistically significant correlation between the presence of TLS and non-mucinous histological type, lower stage tumors, and overall survival. Similar results were reported by Coppola [8] and Trajkovski et al. [10] who assumed that TLS is usually associated with lower grade and good prognosis in CRC and this may be explained by immune-supportive mechanisms attributed to those lymphoid aggregates, however, still contradicting findings were reported.

\section{CONCLUSION}

To sum up, our results assumed that higher expression of Foxp3, CTC, and TLS is associated with favorable prognosis in CRC which reflects the synergistic effect of regulatory T cells and CTC in TME of CRC; however, the exact role for each one still needs more studies, while CD68 needs further work to precisely evaluate its exact role in CRC.

\section{ACKNOWLEDGMENT}

The author of this manuscript would like to express the deepest gratitude to all who suggested this research and appreciate their unforgettable support as well as their generous efforts in the evaluation of this work.

\section{AUTHORS' CONTRIBUTIONS}

The author announces that this work was done by the authors named in this article.

\section{CONFLICTS OF INTEREST}

The authors declare that they have no conflicts of interest.

\section{REFERENCES}

1. Aithal RR, Shetty RS, Binu VS, Mallya SD. Colorectal cancer and its risk factors among patients attending a tertiary care hospital in Southern Karnataka, India. Asian J Pharm Clin Res 2017;10:109-12.

2. Bano N, Najam R, Mirza T, Hassan S. Review of colorectal carcinoma and specific disease features in the population of Pakistan. Asian J Pharm Clin Res 2013;6 Suppl 1:13-7.

3. Khalifa SE, Khairy RA, Bassam AM. Expression of cathepsin D and BCL-2 in colorectal carcinoma, and their correlation with proliferation indices. Egypt J Pathol 2016;36:276-81.

4. Marley AR, Nan H. Epidemiology of colorectal cancer. Int J Mol Epidemiol Genet 2016;7:105-14.

5. Gandomani HS, Yousefi SM, Aghajani M, MohammadianHafshejani AM, Tarazoj AA, Pouyesh V, et al. Colorectal cancer in the world: Incidence, mortality and risk factors. Biomed Res Ther 2017:4:1656-75

6. Peddareddigari VG, Wang D, Dubois RN. The tumor microenvironment in colorectal carcinogenesis. Cancer Microenviron 2010;3:149-66.

7. Bhome R, Bullock MD, Al Saihati HA, Goh RW, Primrose JN, Sayan $\mathrm{AE}$, et al. A top-down view of the tumor microenvironment: Structure, cells and signaling. Front Cell Dev Biol 2015;3:33.

8. Coppola D, Nebozhyn M, Khalil F, Dai H, Yeatman T, Loboda A, et al. Unique ectopic lymph node-like structures present in human primary colorectal carcinoma are identified by immune gene array profiling. Am J Pathol 2011:179:37-45.

9. Posch F, Silina K, Leibl S, Mündlein A, Moch H, Siebenhüner A, et al. Maturation of tertiary lymphoid structures and recurrence of stage II and III colorectal cancer. Oncoimmunology 2018;7:e1378844.

10. Trajkovski G, Ognjenovic L, Karadzov Z, Jota G, Hadzi-Manchev D, Kostovski $\mathrm{O}$, et al. Tertiary lymphoid structures in colorectal cancers and their prognostic value. Open Access Maced J Med Sci 2018;6:1824-8

11. Marks KM, West NP, Morris E, Quirke P. Clinicopathological, genomic and immunological factors in colorectal cancer prognosis. Br J Surg 2018; 105:e99-109.

12. De Divitiis C, Nasti G, Montano M, Fisichella R, Iaffaioli RV, Berretta M. Prognostic and predictive response factors in colorectal cancer patients: Between hope and reality. World J Gastroenterol 2014;20:15049-59.

13. Svennevig JL, Lunde OC, Holter J, Bjørgsvik D. Lymphoid infiltration and prognosis in colorectal carcinoma. Br J Cancer 1984;49:375-7.

14. Rosai J. Special techniques in surgical pathology. In: Rosai J, Ackerman LV, editors. Rosai and Ackerman's Surgical Pathology. $10^{\text {th }}$ ed. Edinburgh: Mosby Elsevier; 2011. p. 37-95.

15. Jakovic LR, Mihaljevic BS, Perunicic Jovanovic MD, Bogdanovic AD, Andjelic BM, Bumbasirevic VZ. The prognostic relevance of tumor associated macrophages in advanced stage classical hodgkin lymphoma. Leuk Lymphoma 2011;52:1913-9.

16. Takenaka M, Seki N, Toh U, Hattori S, Kawahara A, Yamaguchi T, et al. Foxp3 expression in tumor cells and tumor-infiltrating lymphocytes is associated with breast cancer prognosis. Mol Clin Oncol 2013;1:625-32.

17. Chen Z, Chen X, Zhou E, Chen G, Qian K, Wu X, et al. Intratumoral $\mathrm{CD} 8^{+}$cytotoxic lymphocyte is a favorable prognostic marker in nodenegative breast cancer. PLoS One 2014;9:e95475.

18. Sun X, Feng Z, Wang Y, Qu Y, Gai Y. Expression of Foxp3 and its prognostic significance in colorectal cancer. Int J Immunopathol Pharmacol 2017:30:201-6.

19. Ling A, Edin S, Wikberg ML, Öberg Å, Palmqvist R. The intratumoural subsite and relation of $\mathrm{CD} 8(+)$ and Foxp3(+) T lymphocytes in colorectal cancer provide important prognostic clues. Br J Cancer 2014:110:2551-9.

20. Ladoire S, Martin F, Ghiringhelli F. Prognostic role of Foxp3+ regulatory $\mathrm{T}$ cells infiltrating human carcinomas: The paradox of colorectal cancer. Cancer Immunol Immunother 2011;60:909-18.

21. Grimmig T, Kim M, Germer CT, Gasser M, Waaga-Gasser AM. The role of Foxp3 in disease progression in colorectal cancer patients. Oncoimmunology 2013;2:e24521.

22. Michel S, Benner A, Tariverdian M, Wentzensen N, Hoefler P, Pommerencke T, et al. High density of Foxp3-positive $\mathrm{T}$ cells infiltrating colorectal cancers with microsatellite instability. $\mathrm{Br} \mathrm{J}$ Cancer 2008;99:1867-73.

23. Kim M, Grimmig T, Grimm M, Lazariotou M, Meier E, Rosenwald A, et al. Expression of Foxp3 in colorectal cancer but not in treg cells correlates with disease progression in patients with colorectal cancer. PLoS One 2013;8:e53630

24. Zhong X, Chen B, Yang Z. The role of tumor-associated macrophages in colorectal carcinoma progression. Cell Physiol Biochem 2018;45:356-65.

25. Hao NB, Lü MH, Fan YH, Cao YL, Zhang ZR, Yang SM. Macrophages in tumor microenvironments and the progression of tumors. Clin Dev Immunol 2012;2012:948098.

26. Murray PJ, Wynn TA. Protective and pathogenic functions of macrophage subsets. Nat Rev Immunol 2011;11:723-37

27. Ruffell B, Affara NI, Coussens LM. Differential macrophage programming in the tumor microenvironment. Trends Immunol 2012;33:119-26.

28. Qian BZ, Pollard JW. Macrophage diversity enhances tumor progression and metastasis. Cell 2010;141:39-51.

29. Yahaya MA, Lila MA, Ismail S, Zainol M, Afizan NA. Tumourassociated macrophages (tams) in colon cancer and how to reeducate them. J Immunol Res 2019;2019:2368249.

30. Koelzer VH, Canonica K, Dawson H, Sokol L, KaramitopoulouDiamantis E, Lugli A, et al. Phenotyping of tumor-associated macrophages in colorectal cancer: Impact on single cell invasion (tumor budding) and clinicopathological outcome. Oncoimmunology 2016;5:e1106677.

31. Waniczek D, Lorenc Z, Śnietura M, Wesecki M, Kopec A, MucWierzgoń M. Tumor-associated macrophages and regulatory $\mathrm{T}$ cells infiltration and the clinical outcome in colorectal cancer. Arch Immunol Ther Exp (Warsz) 2017;65:445-54.

32. Cui YL, Li HK, Zhou HY, Zhang T, Li Q. Correlations of tumorassociated macrophage subtypes with liver metastases of colorectal cancer. Asian Pac J Cancer Prev 2013;14:1003-7.

33. Forssell J, Oberg A, Henriksson ML, Stenling R, Jung A, Palmqvist R. High macrophage infiltration along the tumor front correlates with 
improved survival in colon cancer. Clin Cancer Res 2007:13:1472-9.

34. Li S, Xu F, Zhang J, Wang L, Zheng Y, Wu X, et al. Tumor-associated macrophages remodeling EMT and predicting survival in colorectal carcinoma. Oncoimmunology 2018;7:e1380765.

35. Chaput N, Svrcek M, Aupérin A, Locher C, Drusch F, Malka D, et al. Tumour-infiltrating CD68+ and CD57+ cells predict patient outcome in stage II-III colorectal cancer. Br J Cancer 2013;109:1013-22.

36. Deschoolmeester V, Baay M, Van Marck E, Weyler J, Vermeulen P, Lardon F, et al. Tumor infiltrating lymphocytes: An intriguing player in the survival of colorectal cancer patients. BMC Immunol 2010;11:19.

37. Sideras K, Galjart B, Vasaturo A, Pedroza-Gonzalez A, Biermann K, Mancham S, et al. Prognostic value of intra-tumoral CD8+/Foxp3+ lymphocyte ratio in patients with resected colorectal cancer liver metastasis. J Surg Oncol 2018;118:68-76.

38. Shibutani M, Maeda K, Nagahara H, Fukuoka T, Matsutani S, Kashiwagi $\mathrm{S}$, et al. A comparison of the local immune status between the primary and metastatic tumor in colorectal cancer: A retrospective study. BMC Cancer 2018;18:371. 